Investigations

\title{
Productive and Biological Features of Kazakh Fine-Wool Sheep in the Conditions of the Almaty Region
}

\author{
Kairat Alimgozhaevich Iskakov, Beibit Turganbekovich Kulatayev, \\ Gulshad Makhambetovna Zhumagaliyeva and Pere Miquel Pares Casanova \\ Kazakh National Agrarian University, 050010, Kazakhstan, Almaty, Abay Street, 8, Kazakhstan
}

\author{
Article history \\ Received: 12-06-2017 \\ Revised: 04-07-2017 \\ Accepted: 04-08-2017 \\ Corresponding Author: \\ Kairat Alimgozhaevich Iskakov \\ Kazakh National Agrarian \\ University, 050010, \\ Kazakhstan, Almaty, Abay \\ Street, 8, Kazakhstan \\ E-mail: iskakov.k.a@mail.ru
}

\begin{abstract}
Kazakh fine-wool sheep bred in semiarid and desert zones of the Kazakhstan South-East are most widely spread in the Republic. However, most sheep do not satisfy the respective requirements of the breed in terms of productivity and especially reproductive capacity. Consequently, increasing the breeding performance and yield of commercial lambs is one of the most urgent issues in fine-wool sheep breeding. One of the tasks for scientists and agricultural specialists is to develop efficient methods to increase the reproductive capacity of fine-wool sheep and preserve lambs to the age of one year, one of the ways to increase the breeding performance being the selection of polycarpous pairs intended to accelerate the breeding rate for the mentioned product.
\end{abstract}

Keywords: Reproduction, Selection, Breeding, Birth Type, Body Weight, Preslaughter Weight, Carcass Weight, Carcass Yield, Visceral Fat

\section{Introduction}

In improving breeds of agricultural animals intended to increase their production capacity, an important aspect is increasing the breeding performance and breeding of polycarpous young stock, since the existence of polycarpous breeds proves the capacity to perform an intra-breed selection with respect to breeding performance.

In relatively favorable conditions of Kazakhstan, the breeding performance of Kazakh fine-wool sheep reached $126-144 \%$, e.g., there are many specimen among these sheep that can yield polycarpous off springs during their lifetime. Achieving this condition by breeding and respective selection has both theoretical and practical value, especially for the Kazakhstan southeast where thin-wool sheep are widely spread. Studying the effect of the sheep birth type on the development of commercially useful features represents scientific and practical interest when breeding to achieve prolificacy.

Consequently, breeding activities in the Kazakhstan fine-wool sheep breeding shall be focused on improving the productive capacity of the existing breeds and lines, e.g., increasing the wool production and improving meat qualities, as well as increasing the sheep natural breeding performance by means of proper breeding (Ermekov and Skorobogatov, 1964).

\section{Study Aim and Tasks}

This paper is aimed to study and improve productive and reproductive qualities of the Kazakh fine-wool sheep.

\section{Material and Study Methodology}

The experimental part of the research was carried out in the R-Kurty breeding farm, Zhambyl district, Almaty oblast.

This paper is dedicated to studying the breeding and selection of sheep in respect to prolificacy, e.g., improving the reproductive qualities of Kazakh finewool gimmers depending on the birth type.

Dams were similar in body weight, age, wool production and wool quality. During tupping, settled dams were individually recorded. After settlement, experimental dams were at the pasture in autumn and winter periods and received no creep-feeding, except for several unfavorable wintering days. In the second half of pregnancy and the lambing period, dams additionally received $1 \mathrm{~kg}$ of alfalfa hay or mixed herbs and $0.3 \mathrm{~kg}$ of crushed barley. During the suckling period, all lambs were in the same flock with dams. After weaning at the age of 4-4.5 months, lambs were divided into two flocks, depending on the gender and were put to the natural pasture. During the winter, from March onwards, dams additionally received concentrated feed represented by 
barley in the amount of $0.3 \mathrm{~kg}$ per animal per day. During other periods of the year, they were kept at the pasture without creep-feeding.

During the mating period, experimental rams received $1.5 \mathrm{~kg}$ of alfalfa hay and $0.3 \mathrm{~kg}$ of crushed barley, apart from the pasture. The dynamics of dam and young stock body weight was studied by weighing to further determine the total and daily average gain of body weight in various periods of after-fetal life.

To assess the linear growth describing the exterior development features at the moment of birth, in weaning and at the age of 1 month, seven measurements were taken in 25-30 gimmers of each group: Height at the shoulder, transverse body length, chest girth, chest breadth, chest depth, height at hips and metacarpus girth. According to the measurements obtained, the following indexes of body built were determined: Lengthiness, blockiness, long-legness, chest massiveness and boniness.

The growth and development were measured under GOST 25955-83 by individual weighing of animals at birth, at the age of 4,12 and 18 months. Based on the data obtained, the daily average and relative body weight gain of young stock were determined.

The reproductive capacity of sheep was measured by using the following indicators: Breeding efficiency and breeding performance of dams according to individual records of settlement and lambing, viability of compared group of lambs in terms of preservation at the moment of weaning.

The biochemical indicators of blood serum in dams of the experimental group were measured at the age of 26 months. Blood was taken from the jugular vein in the morning before feeding. Total protein in serum was measured by RPL-3 refractometer and protein fractions (albumins, globulins) were determined by agarose gel electrophoresis.

The milk production capacity was determined through the body weight gain of lambs at the age of 20 months. For the experiment, 3 groups of dams were formed, 10 animals in each.

The first group included those dams who were born alone, the second one included those who were born as same-sex twins and the third group included dams of different-sex twins.

The economic efficiency of breeding sheep of various origin was measured taking into account the production yield and breeding costs.

All digital materials were processed by the analysis of variance.

\section{Results and Discussion}

The R-Kurta area is located within the desert-steppe zone and is described by continental climate with high daily and annual variance of temperature and varying amount of precipitation. The no-frost period lasts for 64 days varying between 141 to 181 days in various years. First frosts come late in September, the last taking place from April to mid-May.

The climate continental nature is most prominent in summer time. The night and day temperature difference lies within $15-20^{\circ} \mathrm{C}$. The summer is long-lasting and hot, the air temperature going down from September onwards. Autumn is very warm and relatively short. Air day temperatures may reach $25-30^{\circ} \mathrm{C}$, with occasional frosts occurring at night. Winter comes in midNovember or early in December. The coldest months are January and February. Spring is unstable with frequent cold periods. The vegetation is heterogeneous and distributed over zones being closely related to the soil covering. Light-chestnut soils covering the piedmont and wide plain comprise predominantly absinthial and gramineous associations, including Kentucky and bulbous bluegrass, sedge, brome grass, feather grass, sheep fescue, sage, milfoil and other species (Schwerin et al., 2010; Berry, 2017).

The vegetation covering grey desert soils include desert associations represented by Poaceae cenosis. The vegetation of alkaline soils is represented by Artemisia halodendron Turcz. exBesser, various types of saltworts, etc. The tillage is low, occupying 17,600 ha of agricultural lands, or $1.5 \%$. The primary part of the agricultural area represents pastures- 9,120 ha or $50.7 \%$. The fodder base is created by means of natural and improved haymaking, pastures and partial sowing of feeding crops. The yield of feeding crops significantly depends on the natural and climatic conditions of each year. In general, it is low, being as follows: 3.77.3 centner/ha for barley, 6.5-11.5 centner/ha for oats, 128.5-130 centner/ha for annual grasses for green crops, 13.7-14.1 centner/ha for perennial grasses for hay, 210216 centner/ha for green crops, 8.4-8.5 centner/ha for natural hayfields and 9.6 centner/ha for improved hayfields. During the previous years, R-Kurty consumed the amount of fodder which nutrient value equals 427,314-51,781 of fodder units. This amount includes $32.9-42.7 \%$ of pasture fodders, $14-19 \%$ of rough feed, $14.1-17.2 \%$ of concentrated feed, $25.4-32.3 \%$ for succulent feed. This amount includes 45.7 to $50.4 \%$ for sheep breeding, including 22.9-25.5\% of concentrated feed, $0.4-13.2 \%$ of succulent feed, $48.6-53.4 \%$ of rough feed and $84.7-93.2 \%$ of pasture fodders. The farm's sheep breeding is based on intensive use of natural pastures. The sheep are kept at pasture and in the stalls. Starting with the spring period, sheep are kept at the pasture. Since the vegetation of winter pastures contains insufficient amount of nutrient substances, hay and concentrated feed are provided in winter in the amount of 0.2-0.3 kg per animal/day. This is proved by Sarbasov 
(1977) studies: "In winter, the pasture plant formation of the desert zone is described by low carotene content $(2.5$ $\mathrm{g} / \mathrm{kg}$ ), fat (1.2-1.4\%), protein (5-5.5\%), phosphorus (0.04-0.06\%) and very high content of fiber and calcium." In winter, sheep eat 2.5 to $3 \mathrm{~kg}$ of pasture grass per animal per day for 7-8 h. The nutrient value of $1 \mathrm{~kg}$ of natural winter grass is $0.22-0.26$ fodder units with 18 $26 \mathrm{~g}$ of digestible protein. According to calculations, in winter, in the sandy zone, dams should receive by 0.25 0.54 fodder units more, with $37-5 \mathrm{~g}$ of digestible protein, 11.5-18.5 mg of carotene and 2-2.3 g of phosphorus, when they are kept at the pasture and additionally receive 200-300 $\mathrm{g}$ of barley. It should be noted that though the feeding level and the content is low, the young stock of various origin had satisfactory productive capacity. In terms of growth and development of productive qualities, the sheep produced by dams of the Kazakh fine-wool breed showed prominent distinctions, which could be related to their better adaptability to the husbandry conditions in this area.

The sheep breeding efficiency is ensured by creating highly productive and fertile animals. Each breed has a number of indicators, which aggregate allows making conclusions on their reproductive capacity. One of them is the breeding performance. It is the primary assessment of the breeding value of animals.

It has been established that the sheep reproductive capacity is affected by genetic and paratypic factors (feeding, age, etc.).

At the R-Kutry farm of the Almaty oblast, we have work underway to study the productivity and reproductive capacity of the Kazakh fine-wool sheep depending on the birth type and age. Table 1 summarizes the data that show that twin-born dams have higher breeding performance (Irie and Kohira, 2012).

The breeding performance increases with age in both twin-born and single-born dams, but twin-born ones excel in this parameter: In three lambings, their breeding performance increased by $15.6 \%$, whereas that in singleborn dams increased by $9.1 \%$.

We studied the parameters of body weight and measurements of gimmer exterior depending on the birth type. The body weight of single-born gimmers at birth was $4.39 \mathrm{~kg}$, which is higher by $0.66 \mathrm{~kg}$ or $17.7 \%$ than in twin-borns.

At the age of 12 and 18 months, the difference in this parameter is significantly reduced, being $0.80-1.10$ $\mathrm{kg}$, or $2.25-2.70 \%$. From weaning to the age of 18 months, the body weight gain in twin-born gimmers was 19.71 , with $15.75 \mathrm{~kg}$ in single-borns. Therefore, in the after-milking period, the growth intensity in the former is higher than in the latter. Studying the changes of linear parameters in gimmers shows that there is a difference in exterior measurements of single-borns and twin-borns taken at birth, with this difference being in the latter's favor. For example, the height at the shoulder of twin-borns was $34.65 \mathrm{~cm}$, which is less than in single-borns by $2.7 \mathrm{~cm}$ or $7.6 \%$. In terms of the chest breadth, chest girth behind shoulder blades and transverse trunk height, twin-borns are inferior to single-borns by $16.8,10.3$ and $8.4 \%$, respectively. At the age of 12 months, the difference in height at the shoulder between twin-borns and single-borns fell down to $2.1 \mathrm{~cm}$ or $3.2 \%$, the breast breadth to $0.9 \mathrm{~cm}$ or $2.9 \%$. It should be noted that the existing difference in exterior measurements of gimmers at the age of 12 months was inaccurate. The constitutional features and the development degree of animals are described by the indexes of body built. In particular, the indexes of lengthiness and chest blockiness at birth in gimmer twin-borns were lower than those in single-borns. This difference preserved at the age of 12 months, except for blockiness and boniness. In general, the indexes of body built testify relatively intensive growth of all gimmers during the post-natal period. The article contains data for wool production. At the age of one and two years, the wool production of twin-borns was $3.58-4.21 \mathrm{~kg}$ and that of their single-born peers 3.63 $4.32 \mathrm{~kg}$, e.g., less by $1.40-2.61 \%$ and that at the age of three years 4.36 and $4.42 \mathrm{~kg}$, respectively. The results show that the differences this parameter in compared groups are insignificant. The similar difference is observed in the body weight of lambs born by dams that were born as single- or twin-borns Table 2. As seen in Table 2, rams from twin-born dams have a body weight at birth by $0.42 \mathrm{~kg}$ or $10.9 \%$ less than those from single-born dams and gimmers by $0.38 \mathrm{~kg}$ or $10.3 \%(\mathrm{p}>0.999)$ (Zhumadillayev, 2010).

By the time of weaning, the rams from single-born dams had the body weight of $26.45 \mathrm{~kg}$ and excelled their peers from twin-born dams only by $0.2 \mathrm{~kg}$ or $0.85 \%$ and gimmers by $0.18 \mathrm{~kg}$ or $0.73 \%$. Therefore, by the weaning time, the difference in body weight between compared groups of lambs gets even.

During the suckling period, the intensive growth is observed in lambs from twin-born dams, both in gimmers and rams. Their daily average gain from birth to weaning was $0.38 \mathrm{~kg}$ or $0.92 \%$ higher than in their peers from single-born dams. The absolute body weight gain in rams from twin-born dams for the suckling period was $22.37 \mathrm{~kg}$, which is $0.9 \%$ higher than in their peers from single-born dams. The gimmers from double-born dams had the gain of 22.22 $\mathrm{kg}$ by the weaning time, which is $0.86 \%$ higher than in their peers from single-born dams. It was revealed that from birth to weaning, the body weight of lambs from twin-born dams increases by 6.8-7.0 times and that of lambs from single-born dams by 6.2-6.4 times. 
Table 1. Dam breeding performance

\begin{tabular}{|c|c|c|c|c|c|c|}
\hline \multirow[b]{3}{*}{ Parameters } & \multicolumn{6}{|c|}{ Age and birth type } \\
\hline & \multicolumn{2}{|l|}{2 Years } & \multicolumn{2}{|l|}{3 Years } & \multicolumn{2}{|l|}{4 Years } \\
\hline & Single-born & Twin-born & Single-born & Twin-born & Single-born & Twin-born \\
\hline Dams giving lamb & 370.0 & 152.0 & 384.0 & 176.0 & 346.0 & 203.0 \\
\hline Lambs yielded, EA & 395.0 & 180.0 & 415.0 & 218.0 & 401.0 & 272.0 \\
\hline Dam breeding performance, $\%$ & 106.8 & 118.4 & 108.1 & 123.9 & 115.9 & 134.0 \\
\hline
\end{tabular}

Table 2. Lamb body weight, $\mathrm{kg}$

\begin{tabular}{lllllllll} 
& At birth & & & \multicolumn{5}{c}{ At weaning } \\
Birth type of gimmers & Gender & $\mathrm{N}$ & $\mathrm{M} \pm \mathrm{m}(\mathrm{kg})$ & $\mathrm{C}(\%)$ & $\mathrm{n}$ & $\pm \mathrm{m}(\mathrm{kg})$ & $\mathrm{C}(\%)$ & Average daily \\
\hline Single-borns & Ram & 84 & $4.28 \pm 0.05$ & 11.12 & 78 & $26.45 \pm 0.33$ & 11.39 & 184.7 \\
\multirow{2}{*}{ Twin-borns } & Gimmer & 89 & $4.05 \pm 0.04$ & 9.51 & 61 & $26.08 \pm 0.34$ & 10.24 & 183.6 \\
& Ram & 89 & $3.86 \pm 0.05$ & 10.71 & 70 & $26.23 \pm 0.28$ & 10.03 & 186.4 \\
& Gimmer & 64 & $3.67 \pm 0.05$ & 11.53 & 56 & $25.89 \pm 0.34$ & 9.89 & 185.2 \\
\hline
\end{tabular}

Therefore, from birth to the age of one and higher, twin-born lambs had almost equal rates of gain and productive capacity (body weight, wool production, wool length) and in terms of breeding performance, they had a substantial advantage from 11.6 to $18.1 \%$. Methods to increase the productive capacity of Kazakh fine-wool sheep. The R-Kutry breeding farm is one of those farms where Kazakh fine-wool sheep is bred. Since the time when the breed was approved, the farm has been engaged in pure-breeding. The flock of tupping rams was replenished by reproduction only. For the last 10-15 years, the R-Kutry breeding farm has been changing conditions for breeding replacements and feeding adult breeding sheep. This was caused by abruptly deteriorated plant formation at pastures resulted from violating the rules for using them and barley fodder grains. All that led to a significant reduction of the productive capacity of breeding sheep, including linear ones. It can be suggested that the continuous impact of negative fodder conditions on sheep negatively affected the flock's gene pool and impaired the genetic information that was included when the breed was initially created. In these conditions, conventional selection and breeding methods applied so far may hardly improve breeding qualities and productive capacities of sheep in the short run. Therefore, the farm applies introductory breeding of Kazakh fine-wool sheep with Australian merino rams and sperms of foreign breeds. The results of a scientific and production experiment intended to study the settlement of Kazakh fine-wool sheep dams with a frozen sperm of foreign rams of Rambouillet, Polypay, Suffolk, Awassi and Ost-Fris breeds by means of a laparoscope are used at the R-Kutry farm of the Zhambyl district of the Almaty oblast and experiments prove their capacity to improve the productivity and commercial properties of products (wool length, thickness and net yield, increased number of animals with wool grease of light wool). Rams and gimmers were selected from the mongrel animals, which fully corresponded to the requirements of elite and improved breed class I, to be included in the breeding pool. Half-bred rams were used to settle both pure-bred and productive dams; half-bred dams were settled by both pure-bred and half-bred rams. The yield obtained was judged at the age of 1 year according to respective requirements to improve the breed. All animals corresponding to elite and class I in terms of appraising parameters and productive capacity were related to pure-bred Kazakh fine-wool sheep. Others animals, as mongrel ones, were cross-bred with pure-bred rams of Kazakh fine-wool breed. Rams for replacing the flock of tupping rams were selected from the yield obtained in flocks where individual homogeneous selection of parents by primary commercially useful parameters was done (body weight, wool production, wool length and thickness). Classification of dams at the breeding ram was as follows: Elite- 2,181 animals or 24.1\%; class 1-1,610, $26.14 \%$; class II- $3,492,30.2 \%$; class III- $2,213,19.6 \%$ of the total number of dams. Furthermore, there was a breeding core of dams formed in the farm in the amount of 1,551 animals with washed wool production of 3.05 $\mathrm{kg}$. A similar trend is observed in classifications of gimmers and one-year rams, where the number of elite gimmers increased by $15.2 \%$, the number of rams by $19.6 \%$ and class I animals by 16.9 and $21 \%$, respectively. The productive capacity of elite sheep of the farm was greatly changed: The average body weight of primary tupping rams increased by $4.2 \mathrm{~kg}$, that of replacement rams decreased by 0.8 , the same for dams of 2.5 years and older increased by 2.0 , that of gimmers by 2.8; the average wool production increased in all groups for $1.4,0.63,0.21$ and $0.30 \mathrm{~kg}$, respectively; the average wool length for primary tupping rams increased by 1.1 $\mathrm{cm}$, that of replacement rams by 2.1 , the same for the group of dams 2.5 years and older decreased by 0.03 , that of gimmers increased by $1.1 \mathrm{~cm}$. The productive capacity increase is statistically accurate for all groups in terms of body weight, wool production and wool 
thickness ( $\mathrm{td}=2.1$ to 8.7$)$ and the body weight decrease in the group of replacement rams and the wool length decrease in gimmers was statistically inaccurate $(\mathrm{td}=$ 0.15 to 0.70 ). The productivity growth of elite animals was achieved as a result of thorough selection of highly productive sheep and purposeful selection of parent pairs yielded from cross-breeding pure-bred Kazakh fine-wool dams with Australian merinos rams and by improving husbandry and feeding conditions (Kasenov et al., 2011; Smith and Austwirk, 1975).

In general, the productivity of R-Kutry sheep completely meets the requirements of the standard for elite animals and greatly exceeds it in body weight and wool length. As a result of introductory cross-breeding of Kazakh fine-wool dams with Australian merinos rams, the farm managed to breed and use a high number of half-bred tupping rams taking into account that the heritability estimate for wool length is rather high (td 075) and great attention was paid to selection and breeding of long-wool rams predominantly yielded from linear breeding. In most parts of their bodies (back and sides), the rams yielded from introductory crossbreeding had long wool, which is rather favorable for further selection. Primary tupping rams of the farm show high production of washed wool, $56.4 \%$ averagely. More than $85 \%$ of tupping rams at the farm have light brown and white wool grease. According to the above, a conclusion can be made that the sheep stock of the farm has closed wool with light wool grease and rather high yield of pure wool. The thin-wool Kazakh breed was created in the conditions of the year-round pasture husbandry of the Kazakhstan southeast. In the future, the production of this breed will be based on using pasture forage with additional feeding in individual critical periods and when some sheep are switched to fattening. In this connection, one of the most important breeding tasks is to reduce the specific weight of animals with grade 64 wool and to form a flock predominantly comprised of grade 60 wool. As we know, fine-wool sheep have a direct correlation between the wool thickness and the body strength. The thicker is the wool, the stronger is the body. Most tupping rams (68.5\%) have a grade 64 wool. Therefore, further breeding shall be done in order to make the wool thicker. The data obtained for productive capacity of Australian merinos rams show their high wool production-white wool grease and grade 60-64 fine wool; body weight of Kazakh finewool sheep is rather high. To further improve breeding and productive properties of Kazakh fine-wool sheep at the farm, it is necessary to do breeding of the existing lines. The productive capacity of linear animals shows that the parameters are very high and some of them exceed average levels. Using Australian merinos rams for Kazakh fine-wool dams yielded positive results in terms of improving their productive capacity; adapted capabilities of half-bred animals are rather satisfactory and the productive capacity of linear sheep is rather high.
Breeding efficiency of Kazakh fine-wool sheep by lines. Line separation is widely spread in breeding farms of the country. Two lines have been created in the R-Kutry farm where Kazakh fine-wool sheep are bred: I.II-Longwool animals; III-Thick-wool animals. These lines have been created because of the need to increase the body weight, wool length and thickness in these sheep. We studied some productive and biological features of animals within the breeding lines in terms of some commercially useful parameters. As for the body type and productive capacity, linear tupping rams and dams meet the requirements to the meat and wool trend in production and are well adapted to breeding in steppe conditions of the southeastern Kazakhstan. However, the animals differ in primary breeding parameters. Line 1648 rams excel line 548 rams and non-linear rams in body weight by $4.3-7.1 \%$. Long-wool animals $(10.1 \mathrm{~cm})$ excel line 546 rams and non-linear rams in wool length by 4.2$15.4 \%$. The body weight of linear dams is higher than in non-linear ones by $1.8-3.0 \%$ and the wool length and production is higher by 7.1-2.9 and 36.7-32.6\%, respectively. Among the long-wool line animals, there are $99.2 \%$ of dams with MM wool grade.

The wool production of washed wool in rams varies from $6.30 \mathrm{~kg}$ for line 547 to $6.5 \mathrm{~kg}$ for line 1648 , which exceeds breed standards values for the elite class by $12.7-15.4 \%$; that for dams from 2.90 to $3.10 \mathrm{~kg}$, which also exceeds minimal values for the elite by $17.2-22.6 \%$. The wool fineness of tupping rams in thick-wool line 548 has grade 60 and that of long-wool line 1648-grade 60 and 58. More than a half of long-wool dams (65\%) have wool fineness grade 60 , but this line has the least percentage of animals with wool grade 58 (35.0\%). Thick-wool dams have a thinner merinos wool. Dams of both lines have rather high breeding efficiency: $94.5 \%$ for line 1648 and $99.2 \%$ for line 548. Dams of the shortwool line also have high breeding performance-120$120 \%$, with this parameter being $2.0 \%$ less in long-wool dams. The thick-wool line offs prings show better viability. Mortality rate from birth to weaning is $4.5 \%$. Young stock exceeds line 1648 animals in this aspect. Preservation of young stock to the age of 1 year was 87.2-91.4\%. Young stock of all linear and non-linear animals has high growth and development, which is proved by gimmer body weight at birth of 4.1-4.9 kg. Long-wool lambs significantly excel their non-linear peers in this aspect by $25.7 \%$ and thick-wool peers by $10.9 \%$. During the suckling period, lambs grew and developed intensively and by the weaning time, the body weight varied from 31.5 to $36.6 \mathrm{~kg}$. In this aspect, line 1648 young stock excel non-linear and thick-wool ones by 5.1 and $1.9 \mathrm{~kg}$, repetitively. Better growth and development of long-wool lambs is shown by the daily average gain that was $264 \mathrm{~g}$ in gimmers during the suckling period. Thick-wool lambs showed $4.9 \%$ in this parameter, with $13.6 \%$ for non-linear lambs. By the age of 1 year, line 1648 gimmers reached the body weight of 
$43.8 \mathrm{~kg}$, line 548 gimmers reached $42.7 \mathrm{~kg}$ and non-linear gimmers reached $39.8 \mathrm{~kg}$. Line 1648 young stock still excels the peers of other lines by $1.1-4.0 \mathrm{~kg}$ or $2.5-9.1 \%$. Linear one-year gimmers show high wool production in original. The highest wool production is observed in longwool line gimmers and an average value for line 548 exceeds $4 \mathrm{~kg}$ (Lachari and Tasawar, 2013).

Wool length in gimmers at the age of one is 8.0-10.8 $\mathrm{cm}$ and they excel young stock of other groups in this parameter by $0.8-2.8 \mathrm{~cm}$ or $7.4-25.9 \%$. The measurement results for true wool length in various sites in the wool processed for laboratory tests have shown that the longest wool is found in long-wool gimmers on the sides, $11.5 \mathrm{~cm}$ and it excels gimmers of other groups by $1.0-3.1 \mathrm{~cm}$ or $8.7-26.9 \%$. An advantage of this parameter is observed in other sites, such as neck, thigh, back and belly. Balancing of wool along the staple length in various sites is satisfactory. It is most balanced in thickwool gimmers. The average fiber diameter varies from 20.6 to $24.8 \mu \mathrm{m}$ or grade 64 to 60 . On average, the wool fineness in thick-wool gimmers is grade 64; that in longwool gimmers lies between grades 58 and 60 . Biometric processing showed high balancing of wool in terms of fiber fineness in the staple for animals of all groups. Gimmer wool is well balanced in general. When sorting, no more than two or three grades were distinguished. Linear gimmers show differences in wool thickness. The number of animals with wool grade MM in the thickwool line was $72.4 \%$. The wool strength of linear gimmers is described by a sufficiently high breaking length and is $9.29 \mathrm{~km}$ in the long-wool line, 8.13 in the thick-wool line and 7.68 in the non-linear group. The highest strength is observed in the wool of long-wool gimmers, which varies from 8.61 to $9.29 \mathrm{~km}$ depending on the fineness and may reach $10.41 \mathrm{~km}$ in individual animals. Peers in other groups are inferior in these terms by $1.35 \mathrm{~km}$ and $14.6 \%$. In the wool of animals from all groups, the strength is increased together with the fiber diameter. The fat amount in the wool of linear gimmers varies from 18.53 to $24.69 \%$. Somewhat higher is the content of wool grease in the dirty non-degreased wool of thick-wool gimmers characterized by finer wool as compared to other groups. In general, it should be noted that an insufficient amount of grease is present in the wool of linear gimmers and it shows insufficient quality, which is proved by high contamination zones and staple washing zones. Meat productive capacity of young stock in various lines has been studied at the age of 8 months. Fattening capacities of young stock in various lines were studied just after weaning. At first, lambs were grazed at the pasture and at a grain field and when cold weather broke, they were put on feed: 1.5-2.0 $\mathrm{kg}$ of hay and 0.3-0.5 concentrated feed with its increase to $0.6 \mathrm{~kg}$ (Bray, 2010).

The diet nutrient value averagely was 1.66 nutrient units and $168 \mathrm{~g}$ of digestible protein per animal per day. Fattening took 60 days. When putting on feed, the body weight of line 1648 rams was $37.40 \mathrm{~kg}$. When putting on feed, the body weight of line 1648 rams was $37.40 \mathrm{~kg}$; that of line 548 rams was $35.3 \mathrm{~kg}$ and that of the non-linear group was $33.50 \mathrm{~kg}$ and when fattening stopped, the body weight was $49.1,46.5$ and $41.4 \mathrm{~kg}$, respectively. The general gain during the fattening period in line 1648 young stock was $11.7 \mathrm{~kg}$; that in line 548 was $1.2 \mathrm{~kg}$ and that in the non-linear group was $7.6 \mathrm{~kg}$ and the daily average value was 195,187 and $127 \mathrm{~g}$, respectively. The studied meat properties of experimental and control sheep in terms of meat productivity are given in Table 3 .

The analysis of Table 3 results shows that line 1648 lambs bred specifically for wool length and body weight showed high daily average gains. When slaughtering young stock of various lines at the age of 8 months after fattening, 17.5-22.2 kg carcasses were yielded, with the slaughter weight of $18.023 .2 \mathrm{~kg}$ and the slaughter yield of $43.8-47.3 \%$. Here, the predominance was taken by line 164 rams who exceeded their peers from other group in carcass weight by $14-4.7 \mathrm{~kg}$ or $6.3-21.2 \%$ and in slaughter weight by $1.44-5.24 \mathrm{~kg}$ or $6.2-22.5 \%$. The pulpy share in line 1648 young stock was $81.9 \%$, bones contributed to $18.1 \%$, that in line $548-81.5$ and $18.4 \%$, that in the non-linear group- 70.4 and $20.6 \%$; the meatness coefficient was $4.54,4.42$ and 3.86 , respectively. Therefore, line 1648 young sock has a more developed muscular tissue and consequently better meat properties.

Histological studies have shown that gimmers of all groups had rather developed skin by the time of birth. Its total thickness in long-wool young stock was $97.8 \%$ of the skin thickness of gimmers at the age of one year and that in gimmers of other groups was $85.8-91.2 \%$. It should be noted that there are specific differences in the skin structure of gimmers. The thickest skin is found in long-wool gimmers both at birth, weaning and at the age of one year. They excel their peers of the thick-wool line and non-linear gimmers at birth by $234.43 \mu \mathrm{m}$ or $13.3 \%$ and by $139.31 \mu \mathrm{m}$ or $7.9 \%$; at weaning-by $201.33 \mu \mathrm{m}$ or 11.4 and 128.37 or $7.3 \%$; at the age of one -by $97.8 \mu \mathrm{m}$ or 5.4 and $23.48 \mu \mathrm{m}$ or $1.3 \%$. As a result of many years of purposeful breeding work, highly productive Kazakh fine-wool sheep lines were created that differ in individual commercially useful parameters and meet the requirements to independent lines. Line 1648 sheep are characterized by long wool and are higher. Line 548 is typical of thick wool and good balance along its length and fineness of the wool and in the staple. The unwashed wool production for adult dams of various birth types showed that it is higher than in single-born dams by 0.2 $\mathrm{kg}$ or $4.5 \%$ than in twin-born dams of the same or different sex. In terms of washed wool production, this difference was $0.19 \mathrm{~kg}$ or $8.5-7.2 \%$, respectively, e.g., the wool yield in single-born dams was higher (50.9\%) than in twin-born dams (48.8-49.5\%). Studying the economic efficiency of breeding Kazakh fine-wool dams of various types showed that the highest profit (362.4 tenge) and, therefore, the highest profitability belongs to twin-born dams from same-sex broods settled by twin-born tupping rams same-sex broods as well (Chonfeldt et al., 1993). 
Table 3. Meat productivity

\begin{tabular}{|c|c|c|c|}
\hline \multirow[b]{2}{*}{ Parameters } & \multicolumn{3}{|l|}{ Lines } \\
\hline & 1648 & 548 & $\mathrm{~N} / \mathrm{L}$ \\
\hline Pre-slaughter body weight (kg) & 49.10 & 46.50 & 41.10 \\
\hline Carcass weight $(\mathrm{kg})$ & 22.20 & 20.80 & 17.50 \\
\hline Carcass yield $(\%)$ & 45.20 & 44.20 & 42.50 \\
\hline Visceral fat $(\mathrm{kg})$ & 1.06 & 1.02 & 0.52 \\
\hline Visceral fat yield (\%) & 2.16 & 2.19 & 1.26 \\
\hline Slaughter weight $(\mathrm{kg})$ & 23.26 & 21.82 & 18.02 \\
\hline Slaughter yield (\%) & 47.30 & 46.90 & 43.80 \\
\hline
\end{tabular}

In order to increase the productive capacity and the reproductive capacity of Kazakh fine-wool dams, we recommend creating individual groups of dams from same-sex twin-born broods and use twin-born tupping rams from same-sex broods to settle them.

\section{Conclusion}

Methods to increase the sheep breeding performance were developed that allow increasing the dam breeding performance and the production yield of commercial lambs, without reducing the wool production and body weight. The study results are implemented in the R-Kutry breeding farm in the Almaty oblast. The breeding performance advantages of twin-born dams are obvious and studying the economic efficiency of breeding Kazakh fine-wool dams of various types showed that the highest profit and, therefore, the highest profitability belongs to twin-born dams from same-sex broods settled by twinborn tupping rams from same-sex broods as well. In general, the study intended to increase the breeding performance of sheep has shown that the birth type of both dams and tupping rams has a substantial effect upon the breeding performance of Kazakh fine-wool dams.

\section{Author's Contributions}

All authors equally contributed in this work.

\section{Ethics}

The performed studies demonstrated that the obtained results and analysis of allele variety of the two breed could be applied for development of measures aimed at conservation of unique gene pools, well adopted for local natural and climatic conditions.

\section{References}

Berry, D.P., S. Conroy, T. Pabiou and A.R. Cromie, 2017. Animal_breeding_strategies can improve meat quality attributes within entire populations. Meat Sci.

Bray, A., 2010. Central Progeny Test Results. Beef + Lamb New Zealand, pp. 3-5.

Chonfeldt, H.C., W. Bok and R.T. Naude, 1993. Cooking and juices related quality characteristics of goat and sheep meat. Meat Sci., 34: 381-394.

Ermekov, M.A. and Y.A. Skorobogatov, 1964. Milk productive capacity and development of lambs of a new breed group of Kazakh meat and wool half-finewool sheep. Bull. Agric. Sci. Kazakhstan, 12: 48-54.

Irie, M. and K. Kohira, 2012. Simple spot method of image analysis for evaluation of highly marbled beef. Asian-Australas J. Anim Sci., 25: 592-596.

Kasenov, T.K., A.A. Torekhanov and I.T. Karamshuk, 2011. Novaya poroda "Etti merinos" [New Breed of Etti Merinos]. Almaty: KazNIII-LIC.

Lachari, M.N. and Z. Tasawar, 2013. Genetic potentials of loshi sheep of Multan, Pakistan. Scientific J. Anim. Sci., 2: 253-264.

Schwerin, M., S. Schonfeld, V. Drozdovitch, K. Akimzhanov and D. Aldyngurov et al., 2010. The utility of focus group interviews to capture dietary consumption data in the distant past: Dairy consumption in Kazakhstan villages 50 years ago. // J. Dev. Orig. Health Dis., 1: 192-202.

Smith, L. and P. Austwirk, 1975. Influence of weather on sheep wool quality. Sheep Breeding, 8: 246-248.

Zhumadillayev, N.K., 2010. Meat-producing merinos in Kazakhstan. Proceedings of the Ways to Use the Gene Pool of Environmental Diversity in the Desert and Pasture Farmingm (DPE' 10), Samarkand MRNTI, pp: 55-56. 